\title{
صلاحية برنامج إرشادي للزراع في مجال زراعة محصول الفراولة بمحافظة القليويية

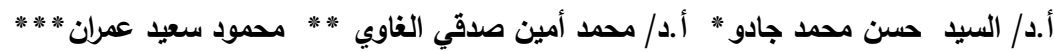

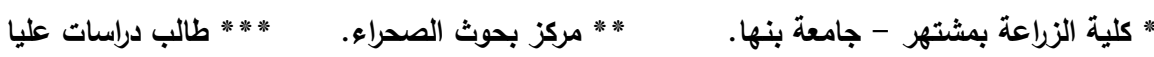

Corresponding author: alsayed.mustafa@ fagr.bu.edu.eg

المستخلص

استهدف البحث دراسة صلاحية البرنامج الإرشادي في مجال زراعة محصول الفراولة بمحافظة القليوبية من وجهة نظر الزراع المتدربين

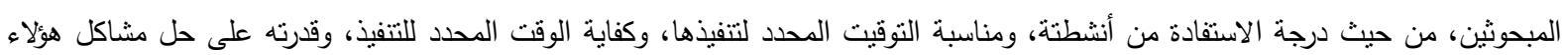
الززاع المبحوثين. وتم إجراء البحث بمركزي شبين القناطر ، وطوخ باعتبارهما أكبر مركزين من حيث المساحة التي تزرع بهما الفراولة بالمحافظة، وتم تحديد

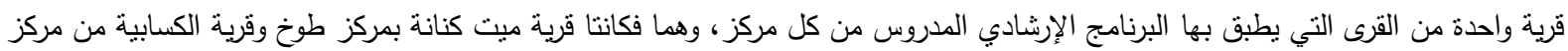

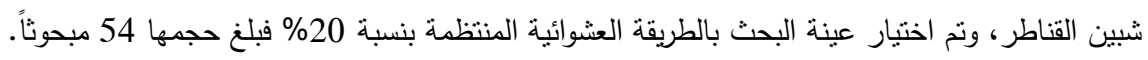

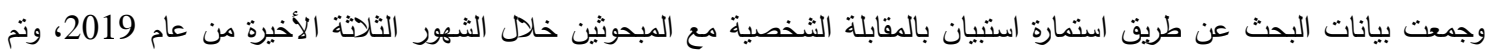

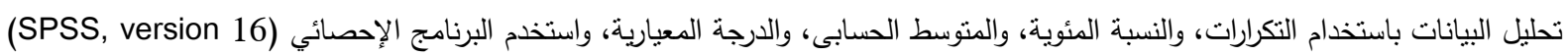
لتحليل بيانات البحث. وتمثلت أهم نتائج البحث فيما يلي: • بلغ المتوسط الحسابي لدرجة الاستفادة من أنشطة البرنامج الإرشادي لمحصول الفراولة 0.74 درجة بنسبة 33.

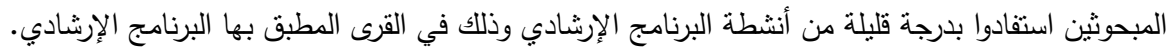

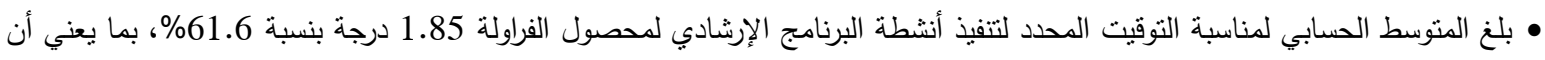

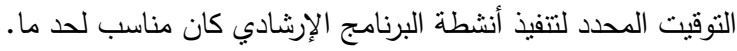

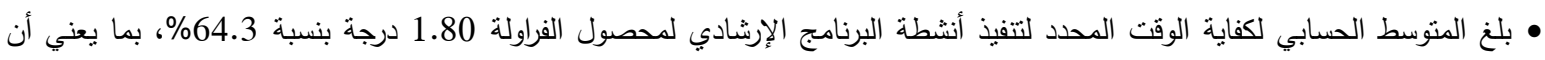

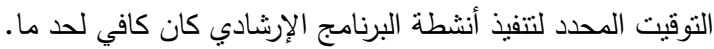

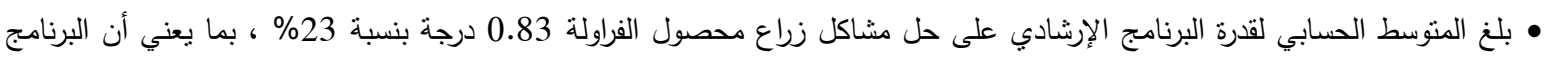

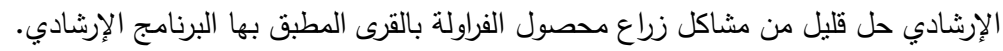

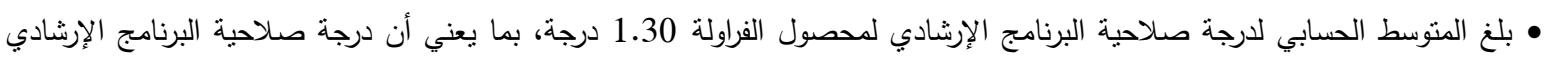

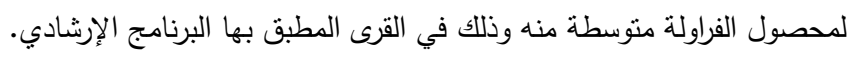

ويتضـح من تلاك النتائج أن: هناك انخفاض فى درجة صـاحلاحية البرنامج الإرثـادي لمحصـول الفراولة من وجهة نظر الزراع المبحوثين

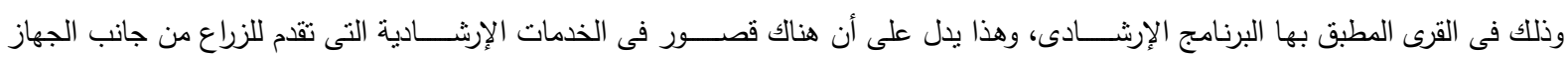

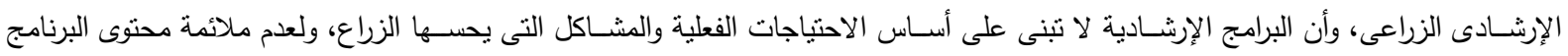

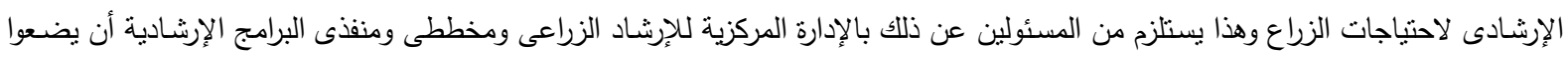

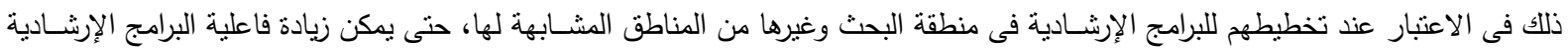

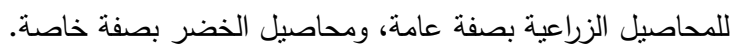
المقدمة والمشكلة البحثية تعتبر الزراعة أحد الهجالات الاقتصادية الهامة التي تنتث فيها مصر سياسة النحرر والإصلاح الاقتصادي، وحتى يكتب لهصر النجاح

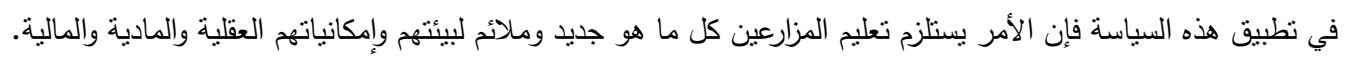

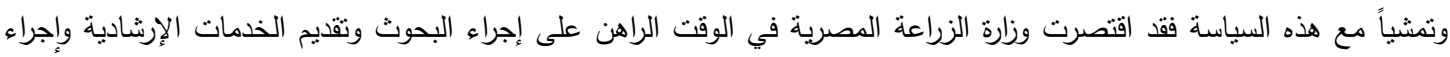

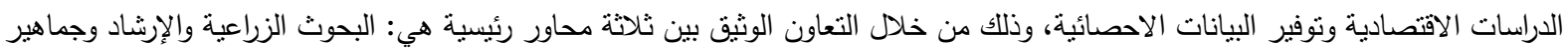
المسترشدين (سوانسن، إ. بيرتون، 1990: ص الإنات 149). 
هذا وأصبحت التتمية وتحديث الزراعة المصرية هي المحور الأساسي لاهتمام المسئولين عن القطاع الزراعي رغبة في رفع مستوى

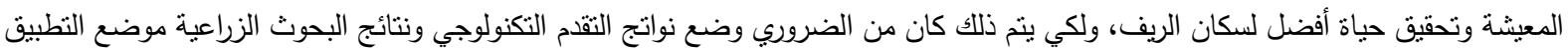

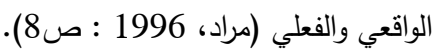
وانطلاقا من ذلك فإنه من المنطقي توقع حدوث تغييرات في النظم والمعلومات والممارسات الزراعية الحالية للتكيف مع هذا المناخ وهذه الفلسفة الجديدة، فقد ذكر قشطة (1996: ص، ص 23 ، 24) أن التغييرات السلوكية هي الهدف النهائي للنشاط الإششادي ولا يمكن حدوث هذا النشاط في غياب هذه التغيرات إذ أن تغيير سلوك المزارع هو الذى يضمن استمراره في تطبيق المستحدثات الزراعية، والتي هي الهدف الأساسي

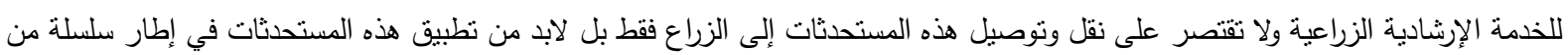

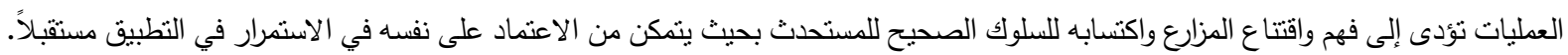

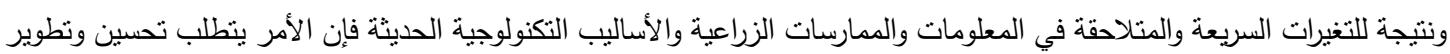
السلوك المعرفي والمهارى للزراع، فلم يعد القدر اليسير من المعرفة الذي يتوارثة المزارعون عن الآباء والأجداد كافيا لمزاولة مهنة الزراعة في العصر ولتهر الحديث.

ويعتبر الارشاد الزراعي أحد المداخل الرئيسية التي يمكن الاعتماد عليها في تحديث الزراعة وتحقيق التتمية الزراعية، ومواكبة التغيرات

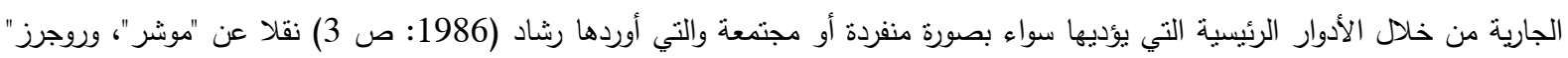

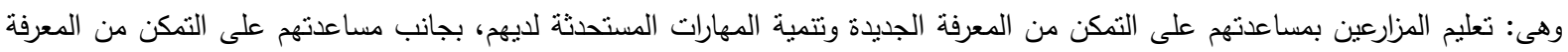
الجديدة وتتمية المهارات المستحدثة لديهم، بجانب مساعدنهم على تتمية موارد جديدة لهم في مجال الإنتاج الزراعي ومدهم بالتكنولوجيا المفيدة وتتجيعهم على الأخذ بالجديد، وتتمبة علاقات الثقة بداخلهم. هذا إلى جانب تغيير العادات والتقاليد الريفية المعوقة لإحداث التتمية الزراعية بما يحدثه ذلك من تغييرات سلوكية مرغوبة في معلومات ومهارات واتجاهات الجمهور الإرشادي، والتي نتبع من الظروف الموقفية المحبطة بالزراع في شكل برامج إرشادية يكون محورها الأساسي مشكلاتهم

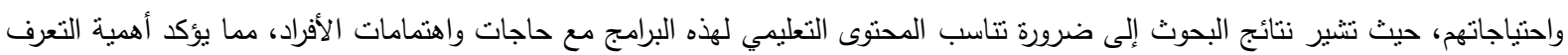

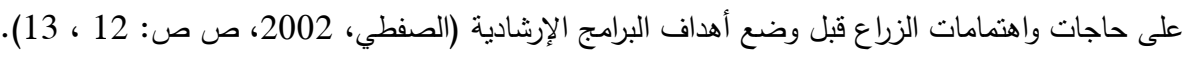
وتعتبر عملية تخطيط البرامج الإرشادية أحد الركائز الأساسية التي يعتمد عليها الإرشاد الزراعي الفعال، وهي وهي عملية تتطلب جهوداً

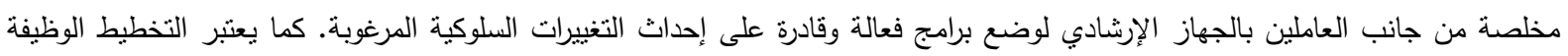

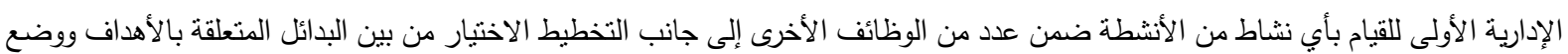

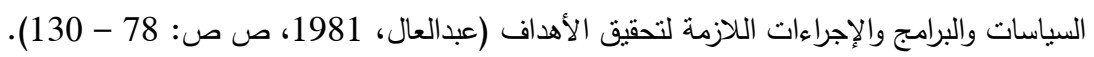
وذكر كلسى وهيرن (1963، ص: 62) أن أنجح البرامج الإرشادية هى تللك البرامج التى تبنى على أساس الموقف الحقيقى بالتعرف على رغبات وحاجات ومشاكل الناس قبل بدء العمل، وهي الأهداف القريبة التى بدونها لا بمكن للتعليم الإرشادى أن يكون فعالاً وناجحاً.

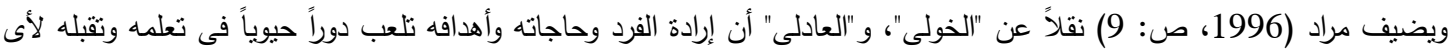

شئ جديد، فالإنسان يتعلم بسرعة إذا ما أحس بأن ما يتعلمه سوف يعود عليه بالنفع ويحل مشاكله القائمة إذا ما اتيحت له فرصة إنها ممارسته. ويعتبر الأساس فى الرجوع إلى الأنشطة أو المهام التى يقوم بها العاملون بأنسان والمشاركون فى عملية تخطيط البرنامج الإرشادى أن يصمم

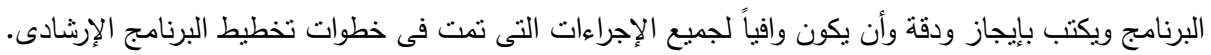
ويقوم جهاز الإرشاد الزراعى عن طريق الإدارة المركزية للإرشاد الزراعي بوضع عداءئ عدد كبير من البرامج الإرشادية الزراعية في مجالات

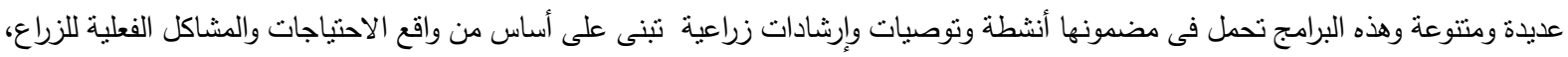
بما يؤدى إلى حصولهم على إنتاج زراعي مرتفع ودرجة جودة عالية حتى تمكنهم من التصدي للمنافسة القوية.

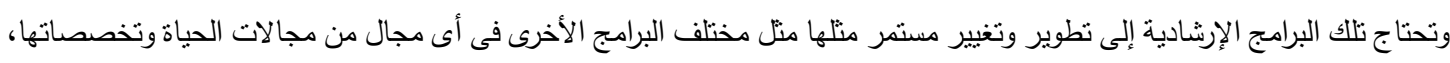
ولا سبيل إلى نجاحها وتحقيق أهدافها المرجوة ووضوحها إلا بالتخطيط العلمى الصحيح والتطوير المستمر لمواكبة التغييرات التي تحدث في بيئة المسترشدين.

هذا ويتطلب إحداث التغيير في سلوك المزارعين تتفيذ العديد من البرامج الإرشادية لزيادة معدلات تتبيهم للممارسات الموصي بها، وبالتالي

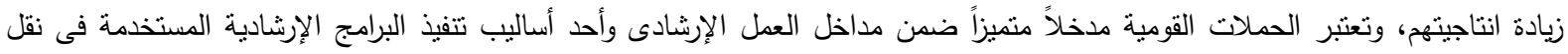

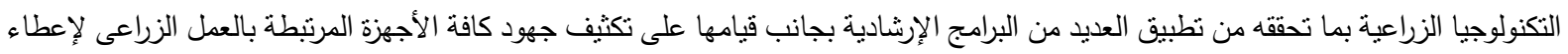
دفعة قوية للمزارعين لنتفيذ التوصيات الفنية المتعلقة بالمحاصيل الحقلية.

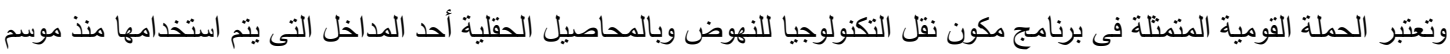
1982/ 1983، ويمكن النظر إلى هذه الحملات على أنها علاقة منبادلة بين البحث والإرشاد الزراعى والمزارعين حيث يتم فيها توحيد جهود الباحثين بئن 
والعاملين بالإششاد الزراعى لنقل التوصيات الفنية الصالحة للنطبيق إلى المزارعين من خلال دراسة الموقف والتعرف على مشكلات زراعة المحاصيل الحقلية، وجمع البيانات اللازمة وتحديد الأهداف لتخطيط برنامج الحملة، وأيضاً وضع وتنفيذ خطة العمل لبرنامج الحملة، وتقييم الأنشطة الإرشادية

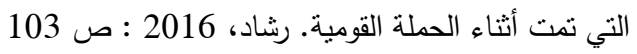
وتعنبر محافظة القليوبية أحد المحافظات الرئيسية المنتجة لمحاصيل الخضر فى مصر وذللك لقربها من محافظتي القاهرة والجيزة وقربها من الأسواق الرئيسية الكبرى مثل سوق العبور ، حيث تمثل المساحة المزروعة بالخضر بالمحافظة حوالي 15860 فدان، وتبلغ مساحة الفراولة منها 4141 فدان من إجمالي مساحة الخضر بالمحافظة وهي تمنل نسبة 26\% نقريبا خلال نفس العام الزراعي 2018 / 2019 (الإدارة المركزية

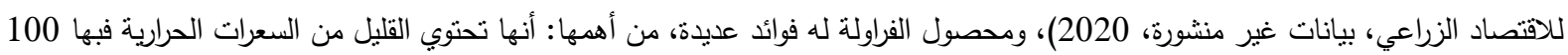
جرام من الفراولة الطازجة تحتوي على 32 سعرة حرارية فقط. كما أنها تتري غذائنا بالفيتامينات والمعادن. لهذا فإن إضافة الفراولة الطازجة إلى النظام

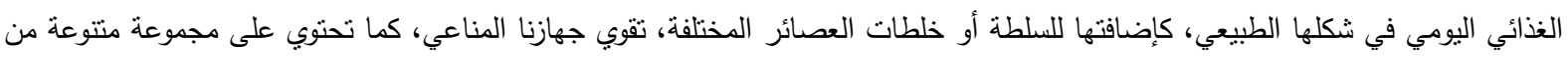
المواد الغذائية على رأسها فيتامين C، حيث أنه في الواقع عند تتاول ثمانية حبات من الفراولة فإنها تحتوي على فيتامين C أكثر من برتقالة واحدة، كما أنها غنية بالمواد المضادة للأكسدة التي تساعد على منع السرطان، وهي مصدر ممتاز لفيتامين K المينه المنجنيز، وحمض الفوليك، والبوتاسيوم،

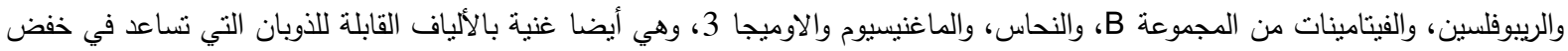

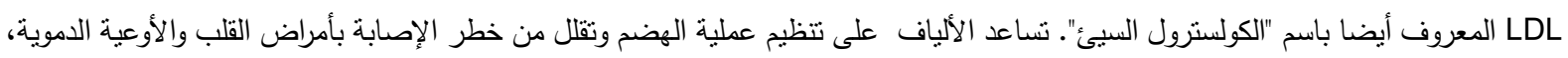

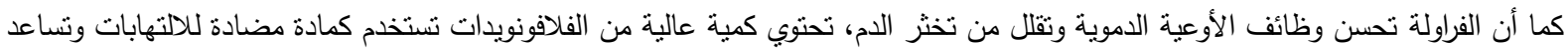
على حماية القلب، بسبب خصائصها المضادة للالتهابات، فهي فعالة أيضاً ضد التهاب المفاصل. (كتيب المشروع التدريبي علي منظومة التكويد

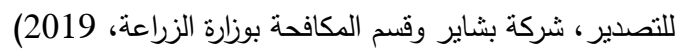
وقد ذكر راضي (2003 : ص 4) نقلاً عن "زاهر"، "الطنوبى" أنه لكى يتم نجاح الإرشاد الزراعي في تحقيق أهداف برامجه المتعلقة

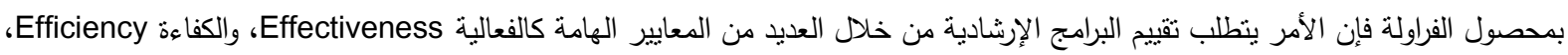

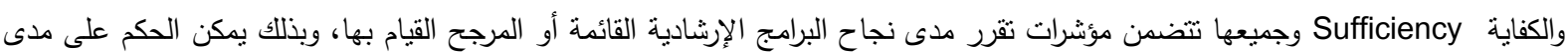
جدوى استمرارها مستقبلاً أو تعديلها أو نوقفها.

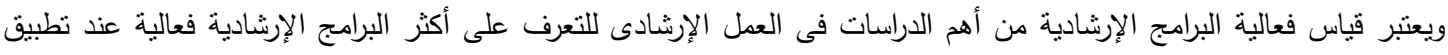

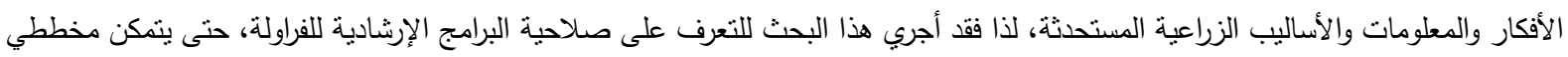

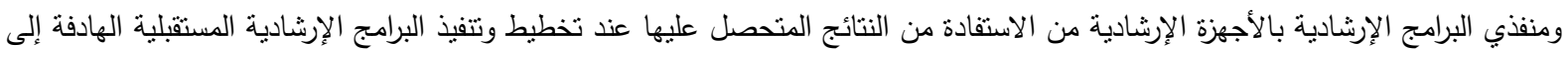

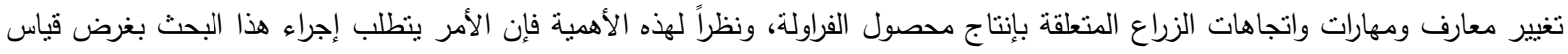
صلاحية برنامج إشادي للزراع في مجال زراعة محصول الفراولة بمحافظة القليوبية.

\section{أهداف البحث}

بناءا على المشكلة البحنية سالفة الذكر أمكن صياغة الأهداف البحثية التالية: 1. التعرف علي درجة استفادة الزراع المبحوثين من أنشطة البرنامج الإششادي المدروس في مجال زراعة محصول الفراولة بمنطقة البحث.

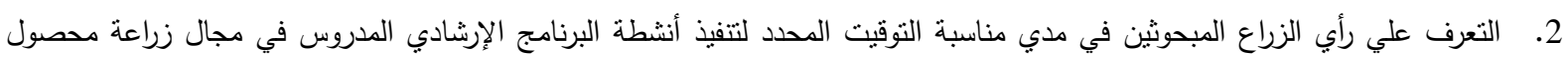
الفراولة بمنطقة البحث.

3. التعرف علي رأي الزراع المبحوثين في مدي كفاية الوقت المحدد لتنفيذ أنشطة البرنامج الإرشادي المدروس في مجال زراعة محصول الفراولة بمنطقة البحث. 4. التعرف علي رأي الزراع المبحوثين في قدرة البرنامج الإرشادي المدروس علي حل مشكلاتهم في مجال زراعة محصول الفراولة بمنطقة البحث.

التعريفات الإجرائية لبعض المصطلحات المستخدمة في البحث:

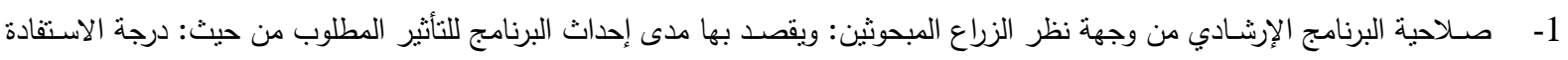

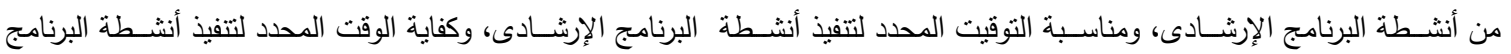
الإرشادي، وقدرة البرنامج الإرشادي على حل مشاكل الزراع.

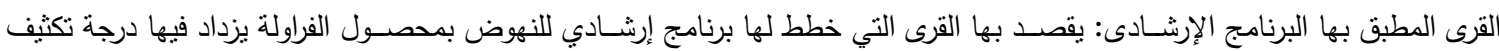


إختيار منطقة البحث والبرنامج الإششادي المدروس:

اختيرت محافظة القليوبية لإجراء هذا البحث بها، نظراً لكونها إحدى المحافظات الرئيسية المنتجة لمحصـول الفراولة في جمهورية مصـر

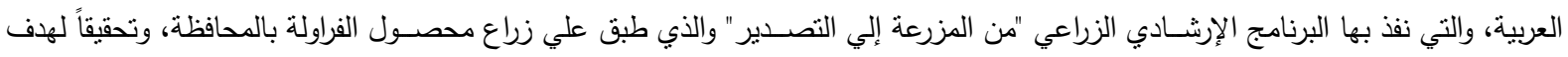

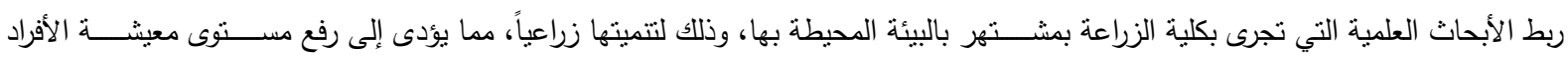
المحليين بها وتحقيق الرفاهية لهم، كما أنها الموطن الأصلـي للباحث مما بيساعد على توفير الوقت والجهد والتسـهيلات التي تتطلبها إجراء الدراسـة

المبدانية.

وتتكون محافظة القليوبية من سـبعة مراكز إدارية هي: بنها، وطوخ، وكفر شـكر، وشـبين القناطر ، والقناطر الخيرية، وقليوب، والخانكة.

ولإجراء هذا البحث تم أخذ أحد البرامج الإرشـادية التي نفتت بالمحافظة وهو برنامج "من المزرعة إلي التصـدير" والذي طبق علي محصـول الفراولة

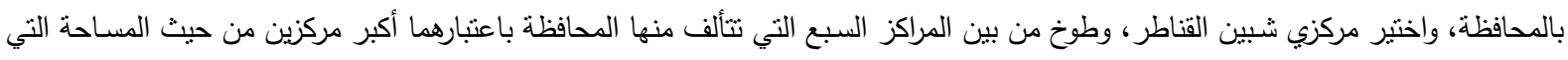

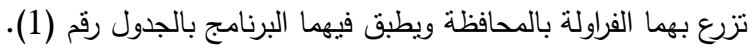

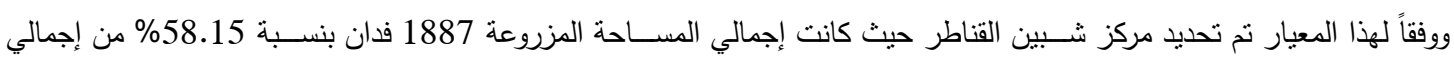
المسـاحة المزروعة بمحصـول الفراولة على مسـتوى المحافظة، ومركز طوخ حيث بلغت المسـاحة المزروعة به 1204 فدان بنسبة 37.15 \% من من

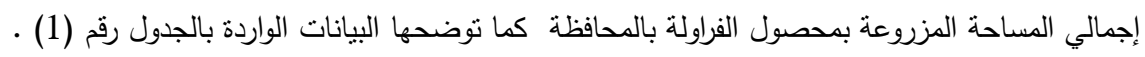

جدول رقم 1. إجمالي مساحات الفراولة بمحافظة القليوبية خلال الموسم الزراعي 2019/2018

\begin{tabular}{|c|c|}
\hline المساحة المزروعة بالفدان & المركز \\
\hline 1887 & ش شبين الفناطر \\
\hline 1204 & طوخ \\
\hline 66 & بنها \\
\hline 57 & قليوب \\
\hline 23 & الخانكة \\
\hline 8 & القناطر الخيرية \\
\hline-- & كفر شكر \\
\hline 3245 & الإجمالى \\
\hline
\end{tabular}

* المصدر : الإدارة المركزية للاقتصاد الزراعي، قسم الاحصاء، بيانات غير منشورة، 2019م.

وأخيراً تم تحديد قرينين من القرى التي يطبق بها البرنامج الإرشـادي من المركزين سـالفي الذكر السـابق تحديدهما بنفس المعيار السـابق بواقع قرية واحدة من كل مركز ، من خلال البيانات الإحصـائية المنوفرة فى قــم الإرثـاد الزراعى بمديرية الزراعة فى محافظة القليوبية فكانت قرية

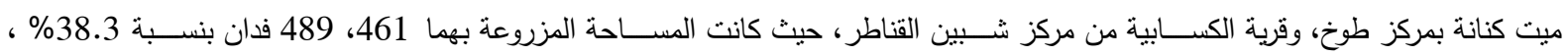
و25.9\% من إجمالي المساحة المزروعة بمحصول الفرولة بالمركزين علي التوالي. جدول رقم 2. إجمالي مساحة الفراولة بمنطقة الدراسة للموسم الزراعي 2019/2018

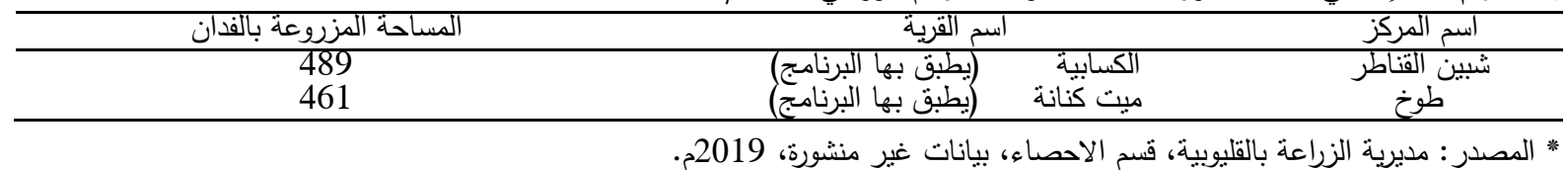

شاملة وعينـة البحث تم اختيار عينة البحث بالطريقة العشـوائية المنتظمة بنسبة 20\% من زراع محصـول الفراولة بكل من القربشين التي طبق بهما البرنامج

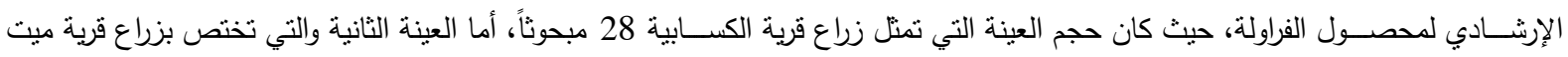

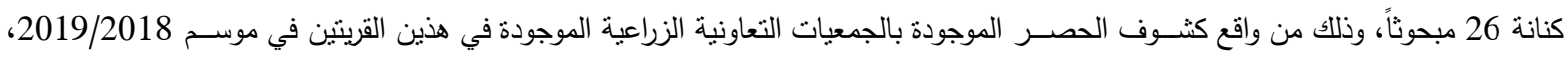

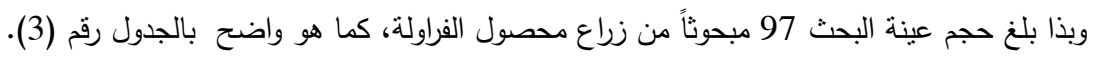

\begin{tabular}{|c|c|c|c|c|}
\hline & & & \multicolumn{2}{|c|}{ توزيع أفراد عينة البحث بالقري المختارة } \\
\hline العينة & عدد الحائزين & \multicolumn{2}{|c|}{ اسم القرية } & اسم المركز \\
\hline 28 & 140 & (بطبق بها البرنامج) & الكسابية & شبين القناطر \\
\hline 26 & 132 & (بطبق بها البرنامج) & ميب كنانة & طوخ \\
\hline 54 & 272 & & المجموع & \\
\hline
\end{tabular}
* المصدر: مديرية الزراعة بالقليوبية، قسم الاحصاء، بيانات غير منشورة، 2019م. 
مصادر وطريقة وأدوات جمع البيانات

اعتمد البحث على مصـدرين للحصــل على البيانات اللازمة لتحقيق أهدافها أولهما: المصـادر الثانوية والتي كانت منمنلة في كل من: قسم الإحصـاء بالإدارة المركزية للاقتصـاد الزراعي بوزارة الزراعة، وقسـم الإحصـاء بمديرية الزراعة ببنها، والوحدة الزراعية بمركزي شـبين القناطر وطوخ، وذلك للحصـــول على البيانات المتعلقة بتحديد منطقة البحث واختيار عينة البحث والحصـــول على المعلومات والتوصــيات الفنية المتعلقة بمحصول الفراولة.

أما ثاني هذه المصـادر فيتعلق بالبيانات التي تم جمعها من مصـادرها الأولية عن طريق المقابلة الثـصـية للمبحوثين بواسطة استمارة

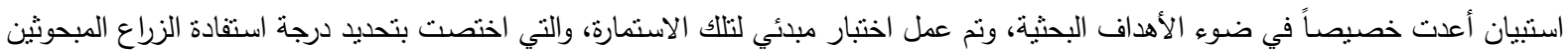
من أنشطة البرنامج الإرشـادي لمحصول الفراولة، ومناسبة التوقيت المحدد لتتفيذ أنشطة البرنامج الإرشادي لمحصول الفراولة، وتحديد كفاية الوقت

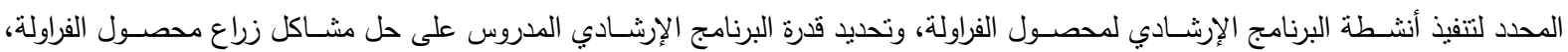

(الادارة المركزية للارشاد الزراعي، بيانات غير منشورة، 2019).

وقد مر إعداد اسـتمارة الاسـتبيان بعدة مراحل حتى بلغت شـكلها النهائي، حيث بدأت بقيام الباحث بزيارة لبعض مناطق إنتاج محصـول

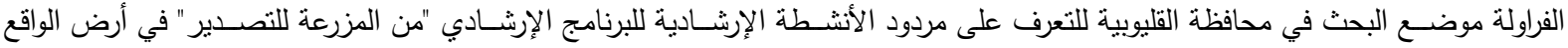

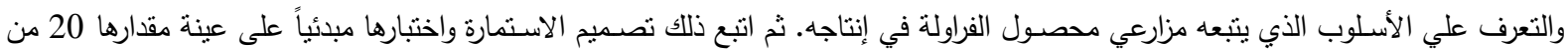

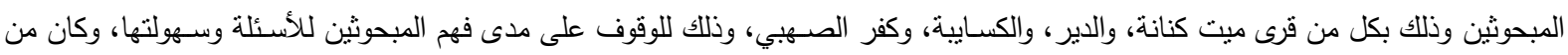
نتائج هذا الاختبار تعديل بعض الألفاظ بما يتمشى مع لغة ومفاهيم المبحوثين في منطقة البحث، ومن ثم أصبحت استمارة الاستبيان في صسورتها

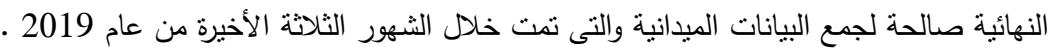

التقدير الكمي للبيانات

تم استخدام أساليب التحويل الرقمي للإجابات على أسئلة استمارة البحث بما يجعلها صالحة للتحليل الإحصائي، لكي تحقق البيانات التي

جمعت أهداف البحث تم تفريغها وتبويبها وجدولتها، وقد تضمن عدة أسئلة لقياس ما يلي:

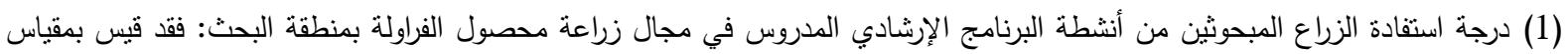

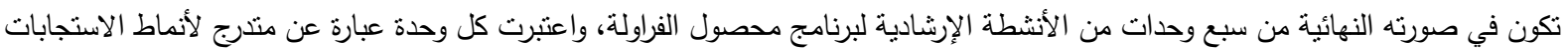

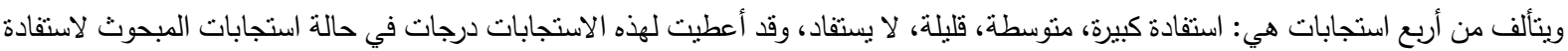
من الأنشطة الإرشادية للبرنامج الإرشادي بدرجة كبيرة أعطي ثلاث درجات، ودرجتين في حالة الاستجابة الدالة على استفادة بدرجة منوسطة، ودرجة

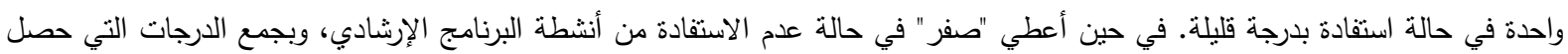
عليها المبحوث من أنشطة البرنامج الإرشادي لمحصول الفراولة، وقد تراوحت الدرجة الكلية للمبحوث ما بين 7 - 21 درجة، وقد نم تقسيم الزراع

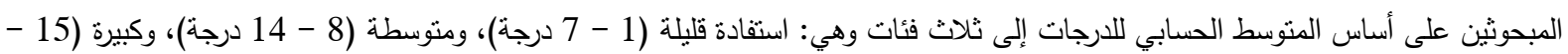
21 درجة)، وتم توزيع كل مبحوث حسب درجته إلى هذه الفئات وهى درجة استفادة قليلة (صفر - 1 درجة)، درجة متوسطة (1.1 - 2 درجة) ،

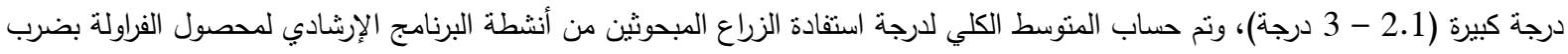

درجة كل فئة في عدد التكرارات الخاصة بها ثم جمعها وقسمة المجموع على عدد المبحوثين.

(2) مناسبة التوقيت المحدد لنتفيذ أنشطة البرنامج الإرشادي المدروس في مجال زراعة محصول الفراولة بمنطقة البحث: تم القياس بسؤال المبحوثين

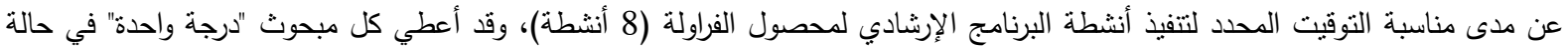
استجابته بعدم مناسبة التوقيت، و "درجتان" في حالة مناسب لحد ما، و "ثلاث درجات" في حالة التوقيت مناسب، وبجمع الدرجات التي حصل علئ عليها المبحوث أمكن الحصول درجة كلية تدل على درجة مناسبة التوقيت المحدد لنتفيذ أنشطة البرنامج الإرشادي لمحصول الفراولة، وقد نراوحت الدرجة الكلية للمبحوث ما بين (1 - 24 درجة)، (1 - 21 درجة)، (1 - 15 درجة) على الترتيب، وقد تم تقسيم الزراع المبحوثين على أساس المتوسط الحسابي للارجات إلى ثلاث فئات هي: غير مناسب (1-8 درجة)، ومناسب لحد ما (9 - 16 درجة)، ومناسب (17 - 24 درجة)، ونت توزيع كل مبحوث حسب درجته إلى هذه الفئات وهى التوقيت غير مناسب (صفر - 1 درجة)، مناسب لحد ما (1.1 - 2 درجة)، مناسب (2.1 - 3 د درجة)، ونم حساب المتوسط الكلي لدرجة استفادة الزراع المبحوثين من أنشطة البرنامج الإرشادي لمحصول الفراولة بضرب درجة كل فئة في عدد التكرارات الخاصة بها ثم جمعها وقسمة المجموع على عدد المبحوثين. (3) كفاية الوقت المحدد لتنفيذ أنثطة البرنامج الإرشادي المدروس في مجال زراعة محصول الفراولة بمنطقة البحث: تم القياس بسؤال المبحوثين

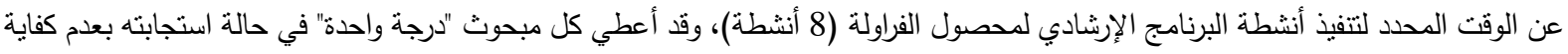
الوقت، و "درجتان" في حالة اذا كان الوقت كافي لحد ما، و "ثلاث درجات" في حالة إذا كان الوقت كافي، وبجمع الدرجات التي حصل عليها المبحوث 
أمكن الحصول درجة كلية تدل على درجة كفاية الوقت المحدد لتنفيذ أنشطة البرنامج الإرشادي لمحصول الفراولة، وقد نراوحت الدرجة الكلية للمبحوث

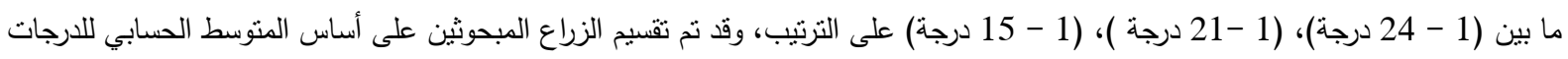

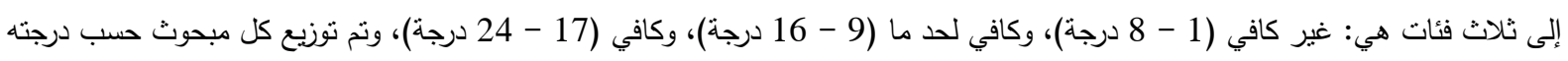

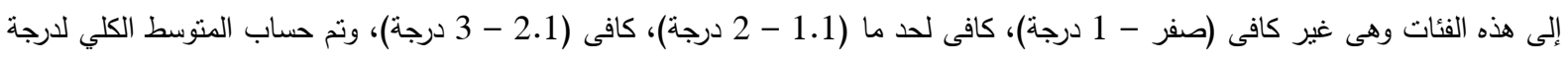
كفاية الوقت المحدد لتتفيذ أنشطة البرنامج الإرشادي بضرب الفئ درجة كل فئة في عدد التكرارات الخاصة بها ثم جمعها وقسمة المجموع على عدد

(4) رأي الزراع المتدربين المبحوثين في قدرة البرنامج الإرشادي المدروس علي حل مشكلاتهم في مجال زراعة محصول الفراولة بمنطقة البحث: تم القياس بسؤال المبحوثين عن قدرة البرامج الإرشادية على حل مشكلاتهم عند زراعة محصول الفراولة، وقد أعطي كل مبحوث "درجة واحدة" في حالة قليل من المشاكل، و "درجتان" في حالة بعض المشاكل، و "ثلاث درجات" في حالة غالبية المشاكل، وقد تم تقسيم الزراع المبحوثين إلى ثلاث فئئات

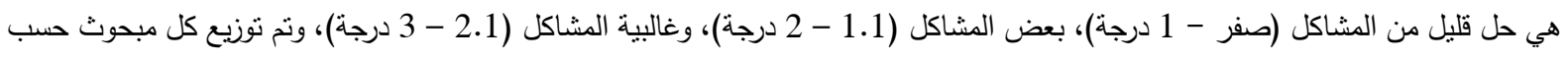
درجته إلى هذه الفئات، وتم حساب المنوسط الكلي لقدرة البرنامج الإرشادي على حل مشاكل زراع محصول الفراولة، بضرب درجة كل فئة في عدد التكرارات الخاصة بها ثم جمعها وقسمة المجموع على عدد المبحوثين.

(5) منوسط درجة صلاحية البرنامج الإرشادي المدروس في مجال زراعة محصول الفراولة بمنطقة البحث وجهة نظر الزراع المتدربين المبحوثين: لقياس هذا المتغير فقد نم حساب الدرجة المعيارية لكل مبحوث فيما يتعلق بالمؤشرات الأربعة المختلفة لقياس صلاحية البرنامج الإرشادي وهي:

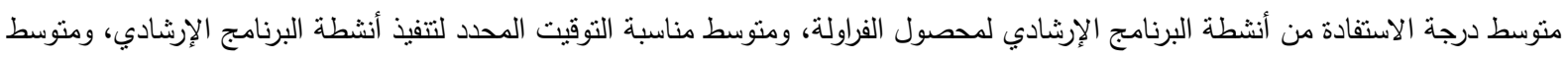
كفاية الوقت المحدد لتنفيذ أنشطة البرنامج الإرشادي المدروس، ومتوسط قدرة البرنامج الإرشادي المدروس على على حل مشاكل زراع محصول الفراولة،

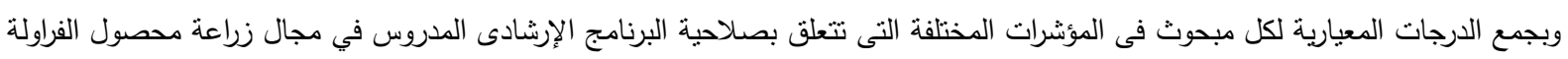

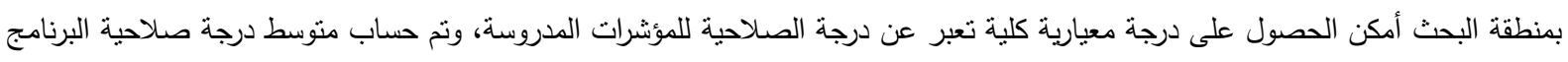

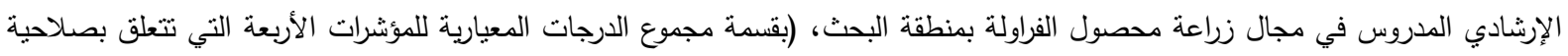

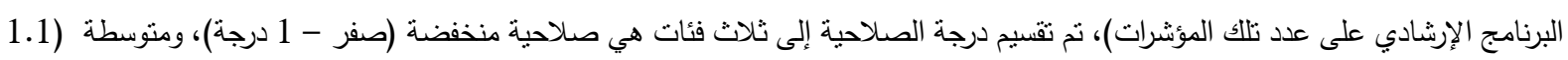

- 2 درجة) ، ومرتفعة (2.1 - 3 د درجة). أدوات التحليل الإحصائي

تم استخدام عدة أساليب إحصائية فى تحليل بياناته وهى: والنسب المئوية، والمتوسط الحسابى، والدرجة المعيارية، هذا فضلاً عن استخدام التكرارات في غرض بيانات البحث، وقد تم تحليل البيانات باستخدام البرنامج الإحصائي (SPSS, version 16).

النتائج ومناقشتها

أولاً: درجة استفادة الزراع المبحوثين من أنشطة البرنامج الإرشادي المدروس في مجال زراعة محصول الفراولة بمنطقة البحث.

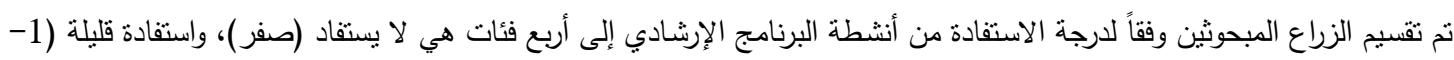
7 درجة) ، ومتوسطة (8-14درجة)، وكبيرة (15- 21 درجة)، وقد حسب العدد والنسبة المئوية لكل منهم كما هو موضتح بالجدول رقم (4) وتبين

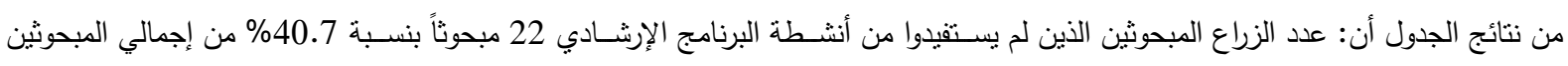
بالعينة، وعدد الزراع المبحوثين الذين اسـتفادوا بدرجة قليلة كان 20 مبحوثاً بنسـبة 37.2 37.

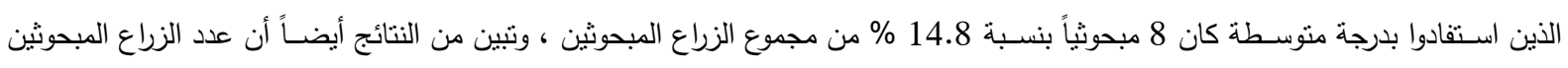
الذين استفادوا بدرجة كبيرة 4 مبحوثين بنسبة 7.4\% من إجمالي المبحوثين بالعينة.

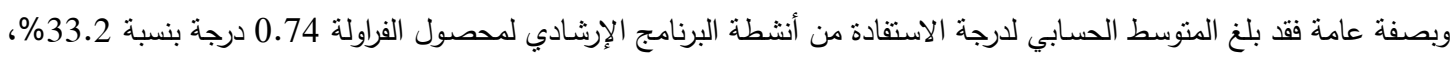
بما يعني أن الزراع المبحوثين استفادوا بدرجة قليلة من أنشطة البرنامج الإرشادي وذلك في القرى المطبق بها البرنامج الإرشادي.

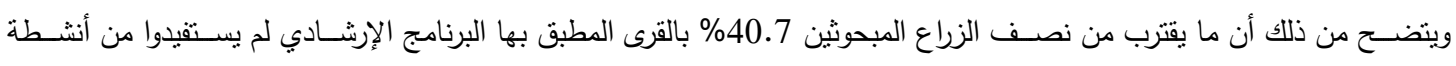

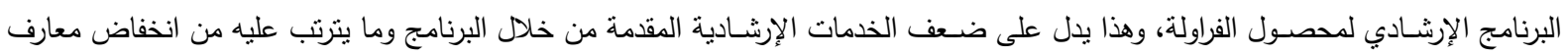

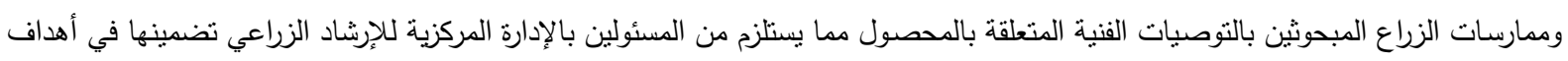

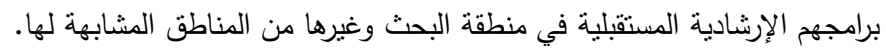




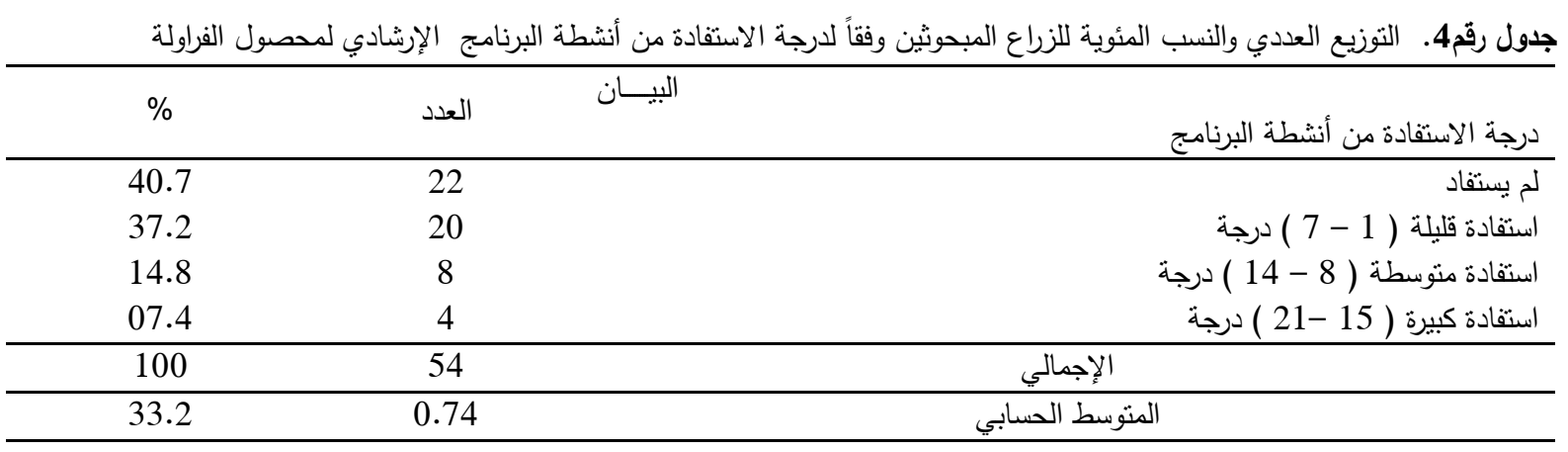

المصدر : حسبت من استمارات الاستنيان.

ثانياً: رأي الزراع المبحوثين في مدي مناسبة التوقيت المحدد لنتفيذ أنشطة البرنامج الإرشادي المدروس في مجال زراعة محصول الفراولة بمنطقة البحث

تم تقسيم الزراع المبحوثين وفقاً لمناسبة التوقيت المحدد لتتفيذ أنشطة البرنامج الإرشـادي إلى ثلاث فئات هي التوقيت غير مناسب (1-

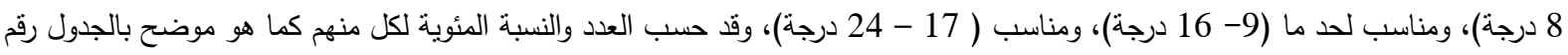

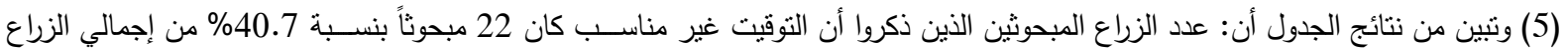

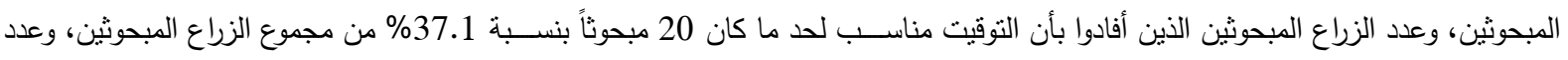

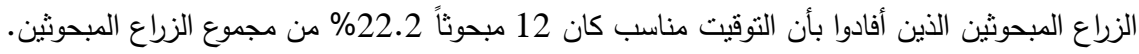
وبصفة عامة فقد بلغ المتوسط الحسابي لمناسبة النوقيت المحدد لتتفيذ أنشطة البرنامج الإرشادي لمحصول الفراولة 1.85 درجة بنسبة 61.57، بما يعني أن التوقيت المحدد لتنفيذ أنشطة البرنامج الإرشادي كان مناسب لحد ما. ويتضح من ذللك أن ما يقرب من نصف الزراع المبحوثين 40.7\% ذكروا أن التوقيت المحدد لتنفيذ أنشطة البرنامج الإرشادي لمحصول

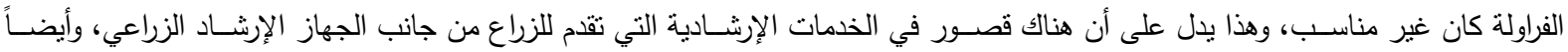

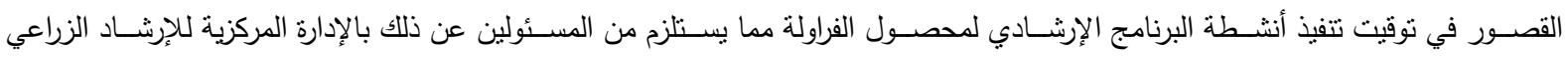
ومخططي ومنفذي البرامج الإرشادية أن يضعوا في الاعتبار عند تصميم البرامج الإرشادية المستقلية.

جدول رقم 5. التوزيع العددي والنسب المئوية للزراع المبحوثين وفقاً لمناسبة التوقيت المحدد لنتفبذ أنشطة البرنامج الإرشادي لمحصول الفراولة

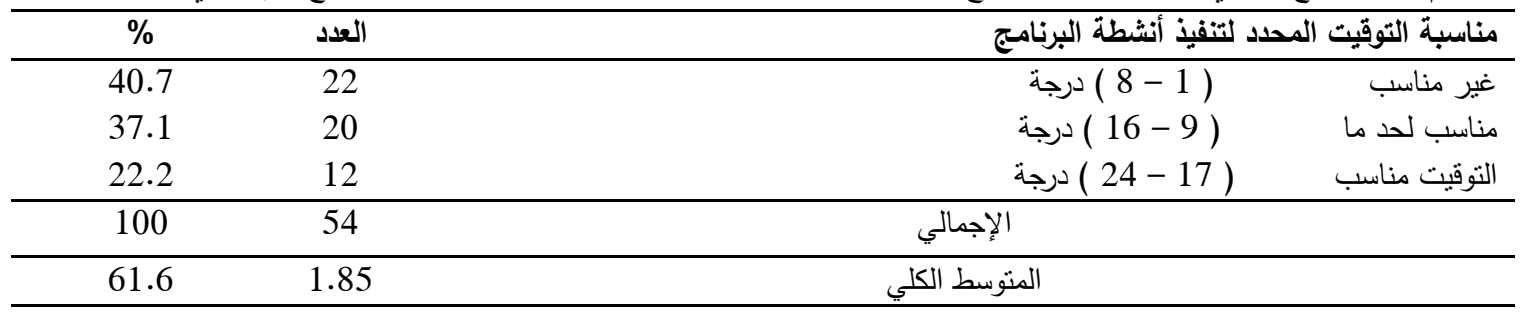

المصدر : حسبت من استمارات الاستنيان.

ثالثاً: رأي الزراع المبحوثين في مدي كفاية الوقت المحدد لتنفيذ أنشطة البرنامج الإرشادي المدروس في مجال زراعة محصول الفراولة بمنطقة البحث: نم تقسيم الزراع المبحوثين وفقاً لرأيهر حول كفاية الوقت المحدد لتتفيذ أنشـة البرنامج الإرشـادي إلى ثنلاث فئات هي الوقت غير كافي

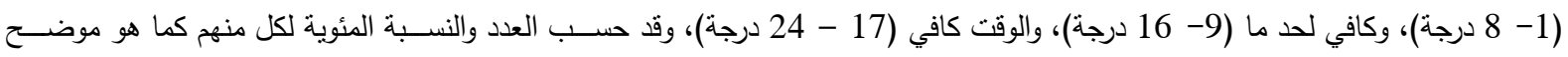

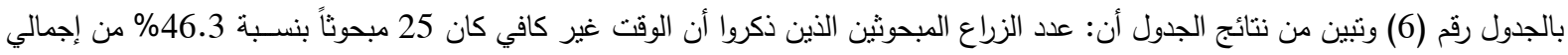

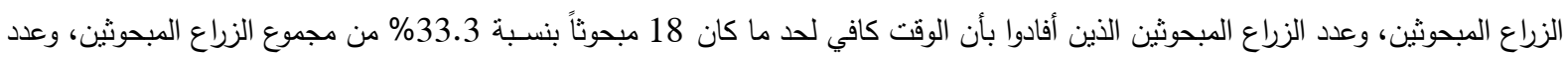
الزراع المبحوثين الذين أفادوا بأن التوقيت مناسب كان 11 مبحوثاً 20.4\% من مجموع الزراع المبحوثين. وبصـفة عامة فقد بلغ المنوسـ الحسـبي لكفاية الوقت المحدد لتتفيذ أنشـة البرنامج الإرشـادي لمحصـول الفراولة 1.80 درجة بنسبة 64.3\% بما يعني أن النوقيت المحدد لتتفيذ أنشطة البرنامج الإرشادي كان كافي لحد ما. 
ويتضح من ذلك أن ما يقرب من نصف الزراع المبحوثين 46.3\% ذكروا أن الوقت المحدد لتنفيذ أنثطة البرنامج الإرشادي لمحصول

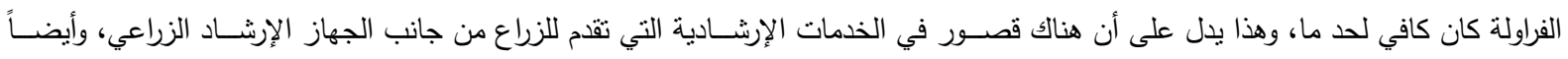

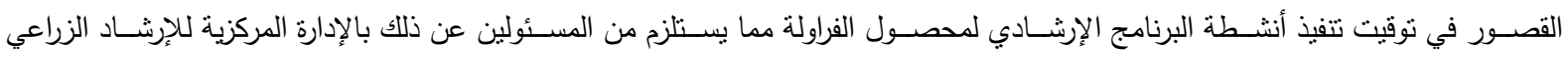
ومخططي ومنففي البرامج الإرشادية أن يضعوا في الاعتبار عند تصميم البرامج الإرشادية المستقبلية.

\begin{tabular}{|c|c|c|c|}
\hline$\%$ & العدد & البيـــان & كفاية الوقت الحددد لتنفيذ أنثشة البرنامج \\
\hline 46.3 & 25 & & غير كافي (1 - 8 ) درجة \\
\hline 33.3 & 18 & & كافي لحد ما (9 - 16 ) درجة \\
\hline 20.4 & 11 & & الوقت مناسب ( 17- 24 ) درجة \\
\hline 100 & 54 & الإجمالي & \\
\hline 64.3 & 1.80 & المتوسط الحسابي & \\
\hline
\end{tabular}

المصدر : حسبت من استمارات الاستنيان.

رابعاً: رأي الزراع المتدربين المبحوثين في قدرة البرنامج الإرشادي المدروس علي حل مشكلاتهم في مجال زراعة محصول الفراولة بمنطقة البحث: تم تقسيم الزراع المبحوثين وفقاً لآرائهم حول قدرة البرنامج الإرشادي على حل مشاكل زراع محصول الفراولة إلى أربع فئئات هي لم يحل

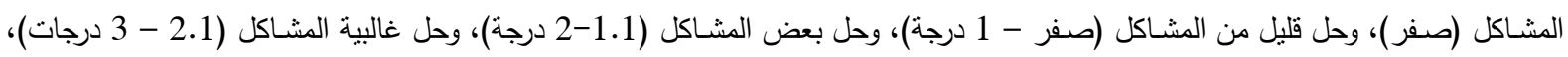

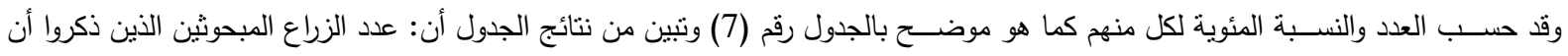

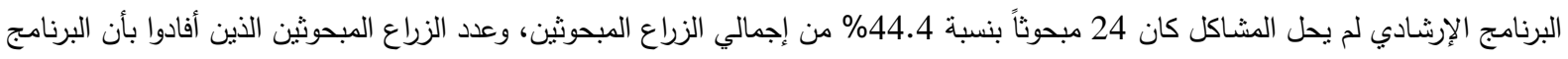

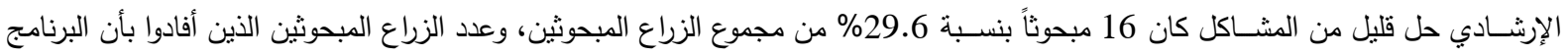

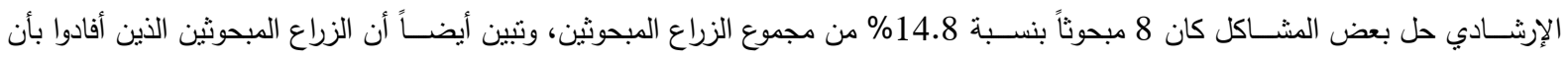

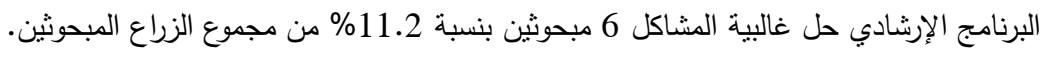

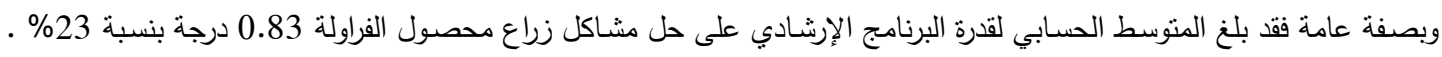

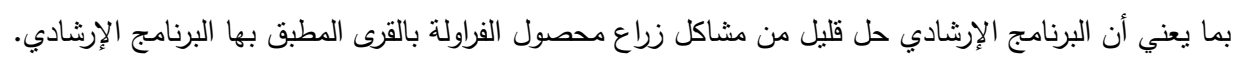

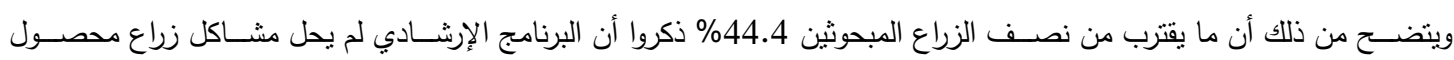
الفزاولة، وهذا يدل على ضعف العمل الإرشادي وقصور في الخدمة الإرشادية التي تقدم للزراع المبحوثين بمنطقة البحث. جدول رقم7. التوزيع العددي والنسب المئوية للزراع المبحوثين وفقاً لدرجة قدرة البرنامج الإرشادي على حل مثاكل زراع محصول الفراولة

\begin{tabular}{|c|c|c|c|}
\hline$\%$ & 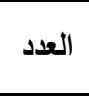 & البيــان & قدرة البرنامج الإرشادي على حل مشاكل الزراع \\
\hline 44.4 & 24 & & لم يحل المشاكل \\
\hline 29.6 & 16 & & حل قليل من المشاكل \\
\hline 14.8 & 8 & & 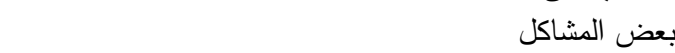 \\
\hline 11.2 & 6 & & 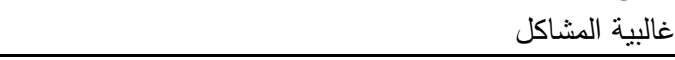 \\
\hline 100 & 54 & & الإجمالي \\
\hline 23 & 0.83 & & المتوسط الحسابي \\
\hline
\end{tabular}

المصدر : حسبت من استمارات الاستيان.

خامساً: متوسط درجة صـلاحية البرنامج الإرشادي البرنامج الإرشـادي المدروس في مجال زراعة محصول الفراولة بمنطقة البحث من وجهة نظر

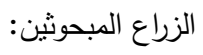

للتعرف على درجة صلاحية البرنامج الإرشادي لمحصول الفزاولة من وجهة نظر الزراع المبحوثين استخدت الدرجة المعيارية كما هو

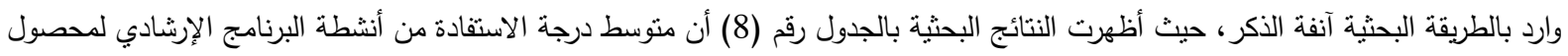


الفراولة كان منخفضاً (0.74) ، وأن متوسط درجة مناسبة التوقيت المحدد لتتفيذ أنثطة البرنامج الإرشادي لمحصول الفراولة كان منوسطاً (1.85)،

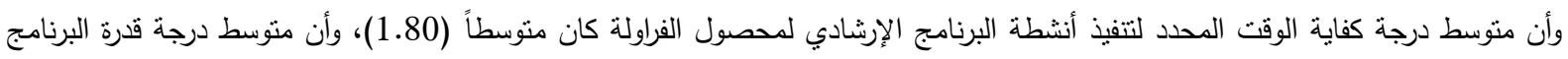

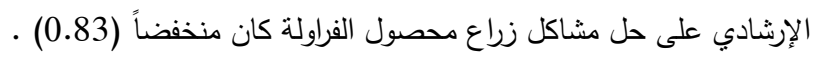

وبصفة عامة فقد بلغ المتوسط الحسابي لدرجة صلاحية البرنامج الإرشادي لمحصول الفراولة (1.30) درجة، بما يعني أن درجة صلاحية البرنامج الإرشادي لمحصول الفراولة منوسطة منه وذلك في القرى المطبق بها البرنامج الإرشادي.

ويتضـح من نلالك النتائج أن: هناك انخفاض فى درجة صـاحية البرنامج الإرشـادي لمحصـول الفراولة من وجهة نظر الزراع المبحوثين وذلك فى القرى المطبق بها البرنامج الارشـــادى، وهذا بدل على أن هناك قصــــور فى الخدمات الإرشــــادية التى تقدم للزراع من جانب الجهاز

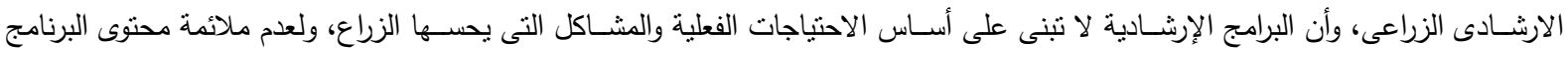

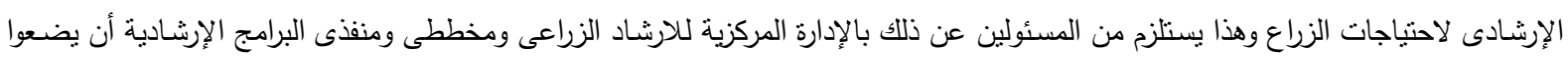

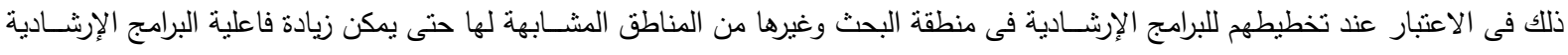
للمحاصيل الزراعية بصفة عامة، ومحاصيل الخضر بصفة خاصة. لإنبا.

جدول رقم 8 ـ متوسط درجة صلاحية البرنامج الإرشادي لمحصول الفراولة من وجهة نظر الزراع المبحوثين

البيـان المتوسط العام بالدرجة المعيارية

مؤشرات صلاحية البرنامج الإرشادي

\begin{tabular}{|c|c|c|}
\hline 0.74 & درجة الاستفادة من أنشطة البرنامج الإرشادي & -1 \\
\hline 1.85 & مناسبة التوقيت المحدد لتتفيذ أنشطة البرنامج الإرشادي & -2 \\
\hline 1.80 & كفاية الوقت المحدد لتتفيذ أنشطة البرنامج الإرشادي. & -3 \\
\hline 0.83 & قدرة البرنامج الإرشادي على حل مشاكل زراع المحصول & -4 \\
\hline 5.22 & الإجمـالي & \\
\hline 1.30 & المتوسط الكلي & \\
\hline
\end{tabular}

المصدر : حسبت من استمارات الاستنيان.

1- وزارة الزراعة واستصلاح الأراضي، الإدارة المركزية للاقتصاد الزراعي، بيانات غير منشورة ، الدقي، 2019. 2- وزارة الزراعة واستصـلاح الأراضس، الإدارة المركزية للإرشـاد الزراعي، زراعة الفراولة في الأراضـي القديمة (أراضـي الوادي والدلتا)، البرنامج

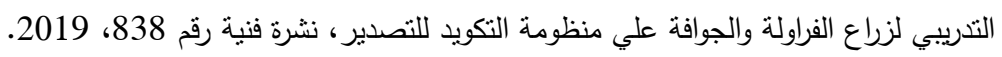
3- الصـفطى، محمد لطفي محمد، دور القيادات الإرشـادية المهنية في فعالية العمل بتنظيم الجهاز الإرشـادي بمحافظات الغربية وكفر الثـيخ والمنوقية، رسالة ماجستير ، كلية الزراعة بكفر الثيخ، جامعة طنطا، 2002. 4- راضي، أحمد مصطفى محمود، كفاءة التدريب الإرشـادي للمرشدين الزراعيين في مصر ، رسـالة دكتوراه، كلية الزراعة، جامعة عين شمس، .2003

5- رشاد، سعيد عباس محمد رشاد (دكتور)، نقل ونشر التكنولوجيا الزراعية، مكتب الهدي للطباعة والنشر، مشتهر طوخ، القليوبية، 2016. 6- رشـاد، سعيد عباس محمد(دكتور)، كفاءة الجهاز الإرشـادي في تتمية وتطوير انتاجية بعض المحاصيل بمحافظة القليوبية، رسالة ماجستير، كلية الزراعة بمشتهر ، جامعة الزقازيق - فرع بنها، 1986. 7- سوانسن، إ. بيرنون، الإرشاد الزراعي - دليل مرجعي، الطبعة الثانية، منظمة الأغذية والزراعة للأمم المتحدة، روما، 1990. 8- قتــة، عبد الحليم عباس (دكتور)، نحو رؤية اتعزيز الخدمة الإرشــادية الزراعية في مصـر ، مجلد مؤتمر اسـتراتيجية العمل الإرشــادي

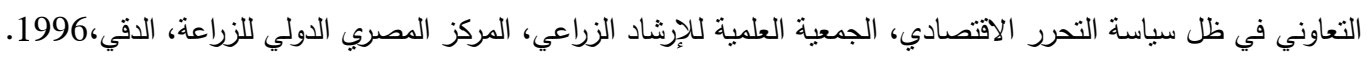




$$
\begin{aligned}
& \text { عبد العال، تحية حامد، مدى فعالية حلقات التاريخ الطبيعي في تتمية بعض المهارات العلمية لدى تلاميذ الصـــف الثاني القســــ العلمي ، }
\end{aligned}
$$

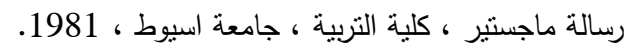

$$
\begin{aligned}
& \text { 10- كلسي، لنكولن دافيد، وهيرن، كانون نتايلز، الإرشاد الزراعي، نرجمة محمد المعلم، مكتبة النهضة المصرية، القاهرة، 1963. } \\
& \text { 11- مديرية الزراعة بالقليوبية، قسم الإحصاء، بيانات غير منشورة، بنها، القليوبية، } 2019 . \\
& \text { مراد، السـيد حسين السـيد طلعت، نحو برنامج إرشـادي لصـيانة موارد التربة والمياه بمحافظة أسـيوط، رسـالة دكتوراه، كلية الزراعة، جامعة } \\
& \text { أسيوط، } 1996 \text {. } 1996
\end{aligned}
$$

\section{The Validity of the Extension Program in the Field of Strawberry Cultivation at Qalyubia Governorate}

Prof. Dr. Elsayed Hassan Mohamed Gado * Prof. Dr. Mohamed Amin Sidqi Al Ghawi ** Mahmoud Saied omran $* * *$

* Faculty of Agriculture - Benha University. ** Desert Research Center *** Postgraduate student

Abstract

The research aimed to study the validity of the extension program in the field of strawberry cultivation at Qalyubia Governorate from the viewpoint of the trained farmers in question, in terms of the degree of utilization of its activities, the appropriateness of the time specified for its implementation, the adequacy of the time specified for implementation, and its ability to solve the farmers' problems.

The research was conducted in the centers of Shebin Al-Qanater, and Toukh, as they are the two largest centers in terms of the area in which strawberries are grown in the governorate, and two of them were identified from the villages in which the studied extension program is applied in the location of one village from each center, namely the village of Mit Kenana in Toukh Center and the village of Kasabiya from the Shibin al-Qanater center 20\% of the sample was chosen by a systematic random method, and its size was 54 respondents.

The search data were collected through a personal interview of the respondents using a questionnaire form during the last three months of 2019, and the data were analyzed using frequencies, percentages, arithmetic mean, and standard score using the statistical program (SPSS).

The most important results of the research were as follows:

-The arithmetic mean of the degree of benefit from the extension program for strawberry crop activities was 0.74 , a score of $33.22 \%$, which means that the researched farmers benefited to a small degree from the extension program activities in the villages where the extension program was applied.

-The arithmetic mean of the appropriate timing for implementing the activities of the extension program for the strawberry crop reached 1.85 points, a percentage of $61.57 \%$, which means that the timing set for implementing the extension program activities was appropriate to some extent.

-The arithmetic average of the adequacy of the time specified for implementing the activities of the extension program for the strawberry crop reached 1.80 , a score of $64.3 \%$, which means that the timing set for implementing the extension program activities was sufficient to some extent.

-The arithmetic average of the pilot program's ability to solve strawberry growers 'problems was 0.83 , with a score of $23 \%$, meaning that the extension program solved few problems of strawberry growers in the villages in which the extension program was applied.

-The arithmetic mean of the degree of validity of the extension program for the strawberry crop was (1.30), which means that the degree of validity of the extension program for the strawberry crop is medium from it in the villages in which the extension program is applied.

It is clear from these results that: There is a decrease in the degree of validity of the extension program for the strawberry crop from the viewpoint of the surveyed farmers in the villages where the extension program is applied, and this indicates that there are deficiencies in the extension services provided to farmers by the agricultural extension system, and that the extension programs are not It is built on the basis of the actual needs and the problems that the farmers feel, and because the content of the extension program is not appropriate to the needs of the farmers, and this requires the officials responsible for that in the Central Administration for Agricultural Extension, planners and implementers of extension programs to take this into account when planning extension programs in the study area and other similar areas, until The effectiveness of extension programs for agricultural crops in general, and for vegetable crops in particular, can be more effective. 